TABLE 1. Benzene heXaCHLORIDE FOUND IN OATTLE BLOODS AFTER ORAL INGESTION

\begin{tabular}{|c|c|c|c|c|}
\hline Animal & $\begin{array}{c}\text { No. of doses } \\
(1 \text { dose }=0 \cdot 25 \\
\text { gm./kilo })\end{array}$ & $\begin{array}{c}\text { Days after } \\
\text { ingestion }\end{array}$ & $\begin{array}{c}\text { Mgm. found } \\
\text { per 100 ml. } \\
\text { blood }\end{array}$ & Method \\
\hline 5592 & $4^{*}$ & $7 \dagger$ & $2 \cdot 3$ & 1 \\
& & 14 & $1 \cdot 7$ & 1 \\
5598 & 1 & 19 & $2 \cdot 1$ & 2 \\
& & 29 & $2 \cdot 1$ & 2 \\
& & 1 & $2 \cdot 5$ & 1 \\
5606 & 1 & 1 & $1 \cdot 5$ & 1 \\
& & 14 & $1 \cdot 1$ & 1 \\
& & 1 & $0 \cdot 4$ & 2 \\
& & 2 & $1 \cdot 7$ & 1 \\
& & 3 & $1 \cdot 1$ & 2 \\
\hline
\end{tabular}

* On four successive days. † Counted from the last of these days.

Although this work is of a preliminary nature, it does appear that the insecticide persists in the blood for some time after oral ingestion, the actual duration depending upon the size of the initial dose. In addition, there is some variation between individual animals. The method used does not, of course, show that the substance determined is benzene hexachloride as administered, but in conjunction with the biological results it would appear that this is so.

TABLE 2. BGNZENE HEXACHLORIDF IN BLOOD AFTER SPRAYING THE SKIN

\begin{tabular}{|c|c|c|c|c|c|c|c|c|}
\hline \multirow{4}{*}{$\begin{array}{l}\text { Deposit on hide, } \\
\text { mgm. } / \mathrm{sq} \text {. ft. } \\
\text { Concentration in blood, } \\
\text { mgm. } / 100 \mathrm{ml} \text {. }\end{array}$} & \multicolumn{7}{|c|}{ Days after spraying } & \\
\hline & $0^{*}$ & 1 & & 3 & & 5 & 6 & 7 \\
\hline & 0 & 41 & 8 & 14 & 10 & 0 & 0 & 0 \\
\hline & 0 & 0 & 0.3 & $2 \cdot 5$ & $2 \cdot 2$ & $0 \cdot 2$ & 0 & 0 \\
\hline
\end{tabular}

By the spraying experiment, it is indicated that at least one cause of the loss of effectiveness of insecticides applied in oil solution to cattle is absorption of the oil through the skin. Thereafter the compound circulates for several days in the blood, as was found after oral ingestion.

I am indebted to Dr. Wilson for the use of some of his experimental animals in these determinations.

Colonial Insecticide Research, F. BARLOW Entebbe, Uganda.

${ }^{1}$ De Meillon, Nature, 158, 839 (1946).

${ }^{2}$ Wilson (in the press).

Neal et al., U.S. Pub. Health Rep. Suppl. No 177 (1944).

\section{'DD' as a Means of Controlling Heterodera rostochiensis (Woll.)}

INVESTIGATIONS during the past four years into the chemical control of $H$. rostochiensis have revealed that chloropicrin, ethylene dibromide, 'Dowfume G', 1-2 dichloropropene and 1-3 dichloropropane (crude 'DD') and two high boiling-point fractions of crude ' $\mathrm{DD}$ ' are all effective soil fumigants. Because of its efficacy, ease in handling and comparative low cost, crude ' $D D$ ' is outstanding among these.

Concentrations up to 75 gallons of 'DD' per acre have been used with varying degrees of success. Soils ranging from almost pure sand to black fen (a deep, non-acid peat soil) were used; to effect a comparative kill a higher concentration was required in the latter than in the former. When 'DD' was in. jected at the 9-in. level, a 95 per cent reduction in plant infection has been achieved under field conditions in sandy soils. Recent laboratory experiments have shown that better results may be achieved when injection takes place at the 3 -in. level.
Experiments involving the use of soil 'seals' have resulted in a 99 per cent reduction in plant infection.

The treated areas should be left undisturbed for a considerable period; also a full crop rotation should intervene before host crops are again exposed to attack. 'DD' has marked phytocidal effects, and seed potatoes have been killed when planted within seven days of soil treatment.

' $D D$ ' has been effective at a wide range of temperatures $\left(33^{\circ}-75^{\circ} \mathrm{F}\right.$.) and also in soils which have been air-dried or contain up to 40 per cent moisture by weight.

Slightly more ethylene dibromide than 'DD' was necessary to produce a comparative kill. The effectiveness of 'Dowfume $G$ ' is considered to be due to the methyl bromide present.

Weed control was also obtained by the use of 'DD' both in England and Southern Rhodesia. In England the plants controlled were all perennials with an existing root system at the time of soil treatment. Control was only obtained on land in Rhodesia which was treated and 'sealed', resulting in one instance in a 100 per cent control of ropoko grass (Eleusine indica, Gaertn.).

'DD' kills a number of soil pests, including wireworms, eutworms and centipedes. Although it is cheaper than all the other fumigants tested, the quantities required to obtain control of potato eelworm are such that the cost of treatment is still too high for economic use in England.

We would like to record the discovery of viable cysts of Heterodera rostochiensis adherent to soil on seed potatoes imported into Southern Rhodesia from Scotland. From two fields in Lincolnshire on which potatoes had not figured in the crop rotations for eleven years, small numbers of living larvæ were recovered from cysts of Heterodera rostochiensis.

A full account of this work will appear in the near future.

Pest Control, Ltd., Cambridge, and

Pest Control (Central Africa), Ltd., Salisbury, Southern Rhodesia.

\section{What is a Dialysate?}

The meaning of the word 'dialysate' as defined in the Oxford Dictionary is indeed apt to induce mental confusion. It did so recently in my own mind, when I had to struggle through an American patent specification, in which the term was actually used in its Oxford Dictionary sense. In my opinion, as well as in that of my collaborators, Dr. Pirie is quite right, and his discussion ${ }^{1}$ supports our decision to use the term 'dialysate' for the part which dialyses through the membrane.

With regard to the part of the system retained by the membrane, Dr. Pirie agrees that the term 'colloid' is unfortunate; this is so because that part need not be a colloid at all. Might I propose the use of the widespread and comprehensive word 'residue'? This term does not admit of any ambiguity, and applies equally well to the processes of distillation, sublimation and even to that of filtration.

H. G. DeRX

Lever Brothers and Unilever N.V. Laboratory, Zwijndrecht, Holland.

${ }^{1}$ Nature, 160, 198 (1947). 